\title{
CARACTERIZAÇÃO DAS CHUVAS EROSIVAS EM URUSSANGA, SC, COM RELAÇÃO AO PADRÃO DE DISTRIBUIÇÃO TEMPORAL ${ }^{(1)}$
}

\author{
Morgana Levati Valvassori ${ }^{(2)}$ \& Álvaro José Back ${ }^{(3)}$
}

\begin{abstract}
RESUMO
O estudo da distribuição temporal de chuvas é realizado com objetivo de caracterizar o padrão de chuva mais frequente. $O$ conhecimento das características físicas das chuvas com relação aos padrões de precipitação permite realizar modelagem matemática de eventos hidrológicos em condições mais próximas às condições reais. $O$ objetivo deste trabalho foi caracterizar as chuvas erosivas em Urussanga, SC, com relação aos padrões hidrológicos de distribuição temporal. Foram usados os pluviogramas da estação meteorológica de Urussanga (latitude $28,31^{\circ} \mathrm{S}$, longitude $49,19^{\circ} \mathrm{W}$ e altitude de $49 \mathrm{~m}$ ) relativos ao período de outubro de 1980 a março de 2012. As chuvas erosivas foram classificadas em padrões avançado, intermediário e atrasado, se a maior intensidade ocorre no terço de duração inicial, intermediário e final, respectivamente. Foram determinadas as características de altura pluvial, duração da chuva, energia cinética, intensidade máxima em $30 \mathrm{~min}$, erosividade e frequência de chuvas mensais de cada padrão de chuva. Verificou-se a ocorrência de 1.221 chuvas erosivas, das quais $651 \mathrm{com}$ perfil avançado; 416 , intermediário; e 154, atrasado. A duração média das chuvas erosivas é de $14,4 \mathrm{~h}$. A média total de intensidade média para as chuvas erosivas foi de $17,4 \mathrm{~mm} \mathrm{~h}^{-1}$. A maior concentração de chuvas (32,9\%) foi observada no intervalo de duração de 6 a $12 \mathrm{~h}$. Para duração inferior a $18 \mathrm{~h}$, ocorre maior frequência de chuvas do padrão avançado; já para acima de $18 \mathrm{~h}$, as frequências de chuvas do padrão avançado e intermediário são semelhantes.
\end{abstract}

Termos de indexação: precipitação pluvial, erosividade, padrões hidrológicos.

(1) Extraído da Dissertação de Mestrado em Ciências Ambientais do primeiro autor. Recebido para publicação em 27 de setembro de 2013 e aprovado em 27 de março de 2014.

(2) Engenheira Ambiental, Instituto de Pesquisas Ambientais Tecnológicas - Universidade Estadual de Santa Catarina. Rod. Gov. Jorge Lacerda, km 4,5. Caixa Postal 3167. CEP 88806-000 Criciúma (SC). E-mail: morganalevati@unesc.net

(3) Pesquisador, Empresa de Pesquisa Agropecuária e Extensão Rural de Santa Catarina. Rod. SC 446, km 16. Caixa Postal 49. CEP 88840-000 Urussanga (SC). E-mail: ajb@epagri.sc.gov.br 


\title{
SUMMARY: CHARACTERIZATION OF EROSIVE RAINFALL IN URUSSANGA, SC, BRAZIL IN REGARD TO THE TEMPORAL DISTRIBUTION PATTERN
}

\begin{abstract}
The study of temporal distribution of rainfall is carried out to characterize the most frequent rainfall patterns. Knowledge of the physical characteristics of rainfall in relation to rainfall patterns allows mathematical modeling to be performed in regard to hydrologic events more nearly approaching real conditions. The objective of this study was to characterize the erosive rains from the municipality of Urussanga, SC, Brazil in regard to hydrological patterns of temporal distribution. Rainfall records from the meteorological station of Urussanga $\left(28.31^{\circ} \mathrm{S}\right.$ latitude, $49.19^{\circ} \mathrm{W}$ longitude, $49 \mathrm{~m}$ altitude) from October/1980 to March/2012 were used. Erosive rainfalls were classified as advanced, intermediate, or late pattern if the greatest intensity occurred in the initial, intermediate, or final third of the rainfall event, respectively. We determined the characteristics of rainfall height in the rain gauge, duration of the rain, kinetic energy, maximum intensity in 30 min, erosivity, and frequency of monthly rainfalls within each rainfall pattern. There were 1,221 erosive rainfalls in the period - 651 with an advanced profile, 416 with an intermediate profile, and 154 with a late profile. The average duration of an erosive rainfall was 14.4 $\mathrm{h}$. The average total for erosive rainfall intensity was $17.4 \mathrm{~mm} \mathrm{~h}^{-1}$. The highest concentration of rainfall (32.9\%) was observed in the 6 to $12 \mathrm{~h}$ range of duration. Rains with a duration of less than $18 \mathrm{~h}$ occurred most frequently in the advanced rainfall pattern, and for durations greater than $18 \mathrm{~h}$, the frequencies of advanced and intermediate rainfall patterns were similar.
\end{abstract}

Index terms: precipitation, erosivity, hydrological patterns.

\section{INTRODUÇÃO}

A mais conhecida forma de degradação do solo é a erosão, que pode ser definida como o arraste da sua camada superficial pela água corrente, pelo vento ou pelos outros agentes geológicos (Araújo et al., 2005). Esse fenômeno pode causar graves danos às terras agrícolas pela perda de nutrientes, constituindo-se o início de vários problemas decorrentes do sedimento no ambiente.

Dentre os principais problemas causados pela erosão, destacam-se a destruição de nascentes, o aumento do risco de desertificação, a remoção da camada fértil e a redução no teor de nutrientes do solo (Carvalho, 2008).

De acordo com Lima (2011), a chuva é um elemento climático que influencia na erosão hídrica do solo por meio do volume, da intensidade e da frequência. Considerando os efeitos da chuva sobre o solo, a característica de maior influência no fenômeno erosivo é a intensidade, seguida da duração, que é complementar e determina a chuva total. Pruski (2009) afirma que, no processo de ocorrência de erosão hídrica, mais importante que os totais anuais precipitados são a distribuição do tamanho, a velocidade e a energia cinética das gotas, a intensidade, duração e frequência, sendo o conjunto desses fatores conhecido como erosividade da chuva.

Além da erosividade, uma característica da chuva relacionada com o processo de erosão hídrica do solo é o padrão hidrológico, que, conforme método desenvolvido por Horner \& Jens (1942), denomina-se avançado, intermediário e atrasado, caracterizados, respectivamente, quando a localização do pico de maior intensidade está no início (primeiro terço), meio (segundo terço) ou fim (terceiro terço) do período de duração da chuva. De acordo com o método, quando há idênticas condições de volume total, intensidade do pico e duração, as chuvas de padrão hidrológico atrasado são, do ponto de vista da erosão do solo, mais danosas, pois o pico de intensidade ocorre no último terço do tempo de duração da chuva, quando o solo contém maior umidade.

Salomão (1999) afirma que para adotar medidas de controle preventivo e corretivo da erosão é imprescindível entender a dinâmica de funcionamento hídrico sobre o solo. Conforme Mendes (2006), para estudo e representação dos processos erosivos do solo, adotam-se modelos com equações matemáticas que são aplicados no dimensionamento de estruturas de controle da erosão, na avaliação de práticas de manejo do solo e no planejamento ambiental. Um modelo amplamente utilizado é a Equação de Perdas de Solo, que pode ser aplicada para prever a perda de solo nas áreas utilizadas para agricultura e nas de recuperação e proteção ambiental, conforme citam Magalhães Filho et al. (2012), e para bacias hidrográficas, como proposto por Arroio Jr. et al. (2012). O Índice de Erosividade é um dos fatores que compõem a equação.

De acordo com Bemfica et al. (2000), os modelos hidrológicos chuva-vazão têm como entrada de dados a precipitação e o conhecimento da distribuição temporal da intensidade da chuva durante as tormentas, que assume grande importância, pois condiciona o volume infiltrado e a forma do hidrograma de escoamento superficial direto. Diversos métodos foram desenvolvidos para obtenção da chuva de projeto, que na sua maioria não visam a reprodução de eventos reais, mas sim situações com efeitos críticos de 
escoamento. Tais procedimentos são obtidos a partir da análise de dados observados de precipitação pluvial da região em estudo e podem ser aplicados em projetos dessa mesma região.

O estudo do padrão de distribuição temporal de chuvas é realizado com objetivo de caracterizar o padrão de chuva mais frequente. Eltz et al. (2001) ressaltam que a maioria dos estudos com chuvas simuladas utiliza um único padrão de chuva, o padrão constante, o que não é coerente em regiões tropicais onde as perdas de solo são mais relacionadas às chuvas de alta intensidade e curta duração. $\mathrm{O}$ conhecimento das características físicas das chuvas com relação aos padrões de precipitação permite realizar com maior precisão estudos com chuva simulada, por utilizar condições mais próximas às condições reais, ou seja, das chuvas naturais (Evangelista et al., 2005).

O objetivo deste trabalho foi caracterizar as chuvas erosivas de Urussanga, SC, com relação aos padrões hidrológicos de distribuição temporal.

\section{MATERIAL E MÉTODOS}

Foram utilizados os dados da Estação Meteorológica de Urussanga (latitude $28,31^{\circ} \mathrm{S}$, longitude de $49,19^{\circ} \mathrm{W}$ e altitude de $49 \mathrm{~m}$ ). O clima da região, de acordo com o sistema de classificação climática de Köppen, é classificado como mesotérmico úmido com chuvas normalmente bem distribuídas e verão quente (Cfa). Segundo Dufloth et al. (2005), a temperatura do mês mais frio está na faixa de 13 a $15^{\circ} \mathrm{C}$, a temperatura média normal varia de 17,0 a
$19,3{ }^{\circ} \mathrm{C}$ e a temperatura média normal das máximas varia de 23,4 a $25,9^{\circ} \mathrm{C}$, e das mínimas de 12,0 a $15,1^{\circ} \mathrm{C}$. A precipitação pluvial total normal anual pode variar de 1.220 a $1.660 \mathrm{~mm}$, com o total anual de dias de chuva entre 102 e 150 dias.

No município de Urussanga, localizado no sul de Santa Catarina, predominam solos classificados, de acordo com Embrapa (1999), em Argissolos (65 \%) e Cambissolos (31\%); em razão do relevo variando de ondulado a forte ondulado, apresentam restrições de uso por causa da suscetibilidade à erosão (Dufloth et al., 2005). As principais culturas agrícolas em relação à área plantada são o fumo, milho e feijão, destacandose ainda a fruticultura com cultivo de banana, pêssego e uva. No cultivo do fumo, adota-se o cultivo mínimo, enquanto o plantio direto é usado em, aproximadamente, 30 e 70 \% das áreas de cultivo do milho e feijão, respectivamente.

Este trabalho foi desenvolvido a partir dos dados de chuva de diagramas do período de outubro de 1980 a março de 2012, seguindo a recomendação de Carvalho et al. (2005) de estudar séries históricas de no mínimo 22 anos. O modelo de pluviógrafo utilizado em Urussanga é do tipo Hellman Fuess, que fornece pluviogramas diários com precisão para chuvas com durações iguais ou superiores a 5 min.

Os dados dos pluviogramas diários, que registram as chuvas em $\mathrm{mm}$ no eixo vertical e o tempo no eixo horizontal, com subdivisões em intervalos de $10 \mathrm{~min}$ em um período de $24 \mathrm{~h}$, foram digitalizados com o programa Gedac (Pedrollo, 1997). As chuvas foram digitalizadas em segmentos com intensidade constante. Foi elaborado um programa de computador em linguagem Delphi para a leitura dos

Quadro 1. Número e altura pluvial média de chuvas erosivas de Urussanga, SC, no período de outubro de 1980 a março de 2012

\begin{tabular}{|c|c|c|c|c|c|c|c|c|}
\hline \multirow{3}{*}{ Mês } & \multicolumn{8}{|c|}{ Padrão de chuva erosiva } \\
\hline & Avançado & Intermediário & Atrasado & Total & Avançado & Intermediário & Atrasado & Total \\
\hline & \multicolumn{4}{|c|}{ Número de chuva } & \multicolumn{4}{|c|}{ Altura pluvial média } \\
\hline Jan. & 88 & 49 & 17 & 154 & 30,1 & 28,4 & 25,9 & 29,1 \\
\hline Fev. & 86 & 44 & 21 & 151 & 29,4 & 30,9 & 21,6 & 28,8 \\
\hline Mar. & 66 & 26 & 12 & 104 & 29,4 & 24,5 & 20,6 & 27,2 \\
\hline Abr. & 37 & 25 & 13 & 75 & 27,6 & 26,6 & 24,3 & 26,7 \\
\hline Mai. & 34 & 25 & 6 & 65 & 34,2 & 40,7 & 51,2 & 38,3 \\
\hline Jun. & 32 & 23 & 10 & 65 & 23,9 & 33,5 & 14,9 & 25,9 \\
\hline Jul. & 29 & 47 & 7 & 83 & 23,9 & 31,5 & 17,7 & 27,7 \\
\hline Ago. & 34 & 27 & 12 & 73 & 28,3 & 33,8 & 25,5 & 29,9 \\
\hline Set. & 47 & 40 & 17 & 104 & 32,5 & 23,3 & 33,4 & 29,1 \\
\hline Out. & 67 & 38 & 12 & 117 & 26,6 & 30,2 & 23,3 & 27,4 \\
\hline Nov. & 71 & 34 & 13 & 118 & 25,8 & 23,3 & 24,5 & 24,9 \\
\hline Dez. & 60 & 38 & 14 & 112 & 27,1 & 36,1 & 22,6 & 29,6 \\
\hline Ano & 651 & 416 & 154 & 1221 & 28,4 & 30,0 & 24,8 & 28,5 \\
\hline
\end{tabular}


dados digitalizados, bem como para a realização dos cálculos.

No programa constam os seguintes procedimentos:

1) Identificação da chuva individual: adotando os critérios sugeridos por Wischmeier \& Smith (1978), foi considerada chuva individual aquela separada da anterior e da posterior por um período mínimo de $6 \mathrm{~h}$ sem chuva ou com menos de $1 \mathrm{~mm}$;

2) Identificação (Reconhecimento) da chuva erosiva: foram consideradas chuvas erosivas aquelas com quantidade igual ou superior a $10 \mathrm{~mm}$, ou igual ou superior a $6 \mathrm{~mm}$, em um período máximo de $15 \mathrm{~min}$ (Cabeda, 1976).

3) Cálculo da energia cinética unitária: a energia cinética unitária de cada segmento uniforme de chuva foi obtida pela expressão proposta por Wischmeier \& Smith (1978), em unidades do sistema internacional:

$$
\mathrm{EC}=0,119+0,0873 \log \mathrm{i}
$$

em que EC é a energia cinética unitária $\left(\mathrm{MJ} \mathrm{ha}^{-1} \mathrm{~mm}^{-1}\right)$; e $\mathrm{i}$, a intensidade da chuva dada em $\mathrm{mm} \mathrm{h}^{-1}$, no segmento considerado;

4) Cálculo (Contagem) da energia cinética do segmento expresso em $\mathrm{MJ}_{\text {ha }}{ }^{-1}$, multiplicando a EC pela quantidade de chuva no respectivo segmento uniforme, isto é:

$$
\mathrm{Ecs}=\mathrm{EC} \mathrm{h}
$$

em que Ecs é a energia cinética do segmento $\left(\mathrm{MJ} \mathrm{ha}^{-1}\right)$; $\mathrm{e} h$, a altura pluviométrica do segmento $(\mathrm{mm})$;

5) Cálculo (Prognóstico) da energia cinética total da chuva, somando-se a energia cinética de cada segmento uniforme, isto é:

$$
\mathrm{EC}_{\mathrm{t}}=\Sigma \mathrm{ECs}
$$

6) Cálculo (Estimativa) da intensidade máxima da chuva em um período de $30 \mathrm{~min}\left(\mathrm{I}_{30}\right)$;

7) Determinação do índice $\mathrm{EI}_{30}$, que representa a erosividade de cada chuva individual e erosiva,por meio da seguinte expressão, conforme Cassol et al. (2008):

$$
\mathrm{EI}_{30}=\mathrm{EC}_{\mathrm{t}} \mathrm{I}_{30}
$$

em que $\mathrm{EI}_{30}$ é o índice de erosividade da chuva erosiva individual ( $\left.\mathrm{MJ} \mathrm{mm} \mathrm{ha-1} \mathrm{h}^{-1}\right) ; \mathrm{EC}_{\mathrm{t}}$, a energia cinética total da chuva (MJ ha $\left.{ }^{-1}\right) ; \mathrm{I}_{30}$, a intensidade máxima média de precipitação em $30 \mathrm{~min}\left(\mathrm{~mm} \mathrm{~h}^{-1}\right)$;

8) Obtenção das somas mensais e anuais dos índices $\mathrm{EI}_{30}$ determinados para cada chuva individual e erosiva;

9) Classificação das chuvas em padrões avançado, intermediário e atrasado, de acordo com Horner \& Jens (1942), em que:

- Padrão avançado: quando a maior intensidade ocorre no terço inicial do tempo de duração total da chuva;

- Padrão intermediário: quando a maior intensidade é verificada no terço intermediário; e
- Padrão atrasado: quando a maior intensidade ocorre no terço final do tempo total de duração da chuva.

\section{RESULTADOS E DISCUSSÃO}

São apresentadas, no quadro 1 , as frequências absolutas de chuvas erosivas classificadas nos três padrões de distribuição temporal. Durante o período de estudo, ocorreram 1.221 chuvas erosivas, das quais 651 com perfil avançado; 416, intermediário; e 154, atrasado. O padrão hidrológico avançado ocorreu com maior frequência em todos os meses do ano, com exceção do mês de julho. Martins et al. (2009) obtiveram resultados semelhantes na análise dos padrões hidrológicos da série de 27 anos de chuvas de Hulha Negra, RS.

Conforme Cassol et al. (2008), quando há idênticas condições de volume total, intensidade do pico e duração, as chuvas de padrão hidrológico atrasado são, do ponto de vista da erosão do solo, mais danosas, pois o pico de intensidade ocorre no último terço do tempo de duração da chuva, quando o solo apresenta maior umidade. Nesse mesmo raciocínio, Eltz et al. (2011) consideram a maior frequência de chuvas do padrão avançado como benéfico, pois no início da chuva o solo está mais seco e tem condições de absorver mais água.

O padrão avançado foi o de maior ocorrência, correspondendo a 53,31\% do total de chuvas erosivas, seguido pelo intermediário (34,07\%) e atrasado (12,61\%). Eltz el al. (2011), analisando série de 31 anos de chuva de Encruzilhadinha do Sul, RS, constataram a ocorrência do padrão avançado em $48 \%$ das chuvas erosivas, enquanto os padrões intermediário e atrasado tiveram, cada um, $26 \%$ das chuvas erosivas. $\mathrm{O}$ mês de janeiro concentrou o maior número de chuvas no padrão avançado e no intermediário. Já no atrasado, o maior número de chuvas ocorreu em fevereiro. No total das médias mensais, os meses de janeiro e fevereiro concentraram $25 \%$ do total de chuvas erosivas.

Resultados semelhantes foram obtidos por Back (2011), o qual determinou os padrões de distribuição temporal de chuvas intensas de Urussanga, de acordo com o método de Huff (1967). Nesse método, as chuvas do tipo I são aquelas que a maior precipitação ocorre no primeiro quartil da duração, isto é, até $25 \%$ da duração; as do tipo II, a maior parte da precipitação ocorre no segundo quartil, isto é, no intervalo de 25 a $50 \%$ da duração; e assim respectivamente paras os tipos III e IV. Com 132 chuvas intensas selecionadas, Back (2011) observa que as chuvas do tipo I são mais frequentes, seguidas do tipo II. Esse autor também constata que as chuvas dos tipos I e II ocorrem predominantemente no verão, e as do tipo III e IV são distribuídas ao longo do ano. 
As chuvas concentradas no padrão avançado, conforme verificado neste estudo, tendem a gerar menores perdas de solo, pois conforme, Mehl et al. (2001), quando a maior intensidade ocorre no primeiro terço o solo está menos úmido, comparando aos demais padrões, ocorrendo desagregação, selamento superficial e transporte das partículas em menor quantidade do que nos outros padrões de chuva.

Os valores da altura pluvial média das chuvas erosivas para os padrões avançado, intermediário e atrasado encontram-se no quadro 1. Na média anual, os valores de altura pluvial média das chuvas erosivas foram 28,4; 30,0; e 24,8 mm, respectivamente para os padrões avançado, intermediário e atrasado. Nos três padrões, a maior média de altura pluvial foi registrada no mês de maio, sendo $34,2 \mathrm{~mm}$ para o padrão avançado; 40,7, intermediário; e 51,2 mm, atrasado.

No quadro 2, evidenciam-se as médias mensais e anuais de duração das chuvas erosivas. A média geral da duração das chuvas erosivas foi de 14,4 h. A média anual foi de $13,0 \mathrm{~h}$ para as chuvas de padrão avançado; $16,3 \mathrm{~h}$, intermediário; e 15,2 h, atrasado. $\mathrm{O}$ mês de maio concentrou as maiores médias mensais de duração para os três padrões. Houve tendência de menores durações de chuvas nos meses da estação de verão e maiores nos da de inverno. Essa constatação deve-se em parte ao fato de no verão predominarem as chuvas intensas do tipo convectivo, que são caraterizadas pela curta duração, enquanto no inverno prevalecerem as do tipo frontais, distinguidas pela longa duração. Resultados semelhantes foram obtidos por Back (2011).
O Índice de Erosividade da chuva é o produto da energia cinética da chuva pela intensidade máxima ocorrida em qualquer período de 30 min consecutivos. No quadro 2,são apresentadas as médias mensais e anuais da energia cinética (EC); no quadro 3, são apresentadas as médias mensais e anuais da intensidade (I) das chuvas erosivas de Urussanga, $\mathrm{SC}$, classificadas em padrões de distribuição temporal.

Os meses de janeiro e fevereiro apresentaram as maiores médias mensais de energia cinética para as chuvas erosivas de padrão avançado (6,6 $\left.\mathrm{MJ} \mathrm{ha}^{-1}\right)$. Para os padrões intermediário e atrasado, o mês de junho evidenciou os maiores valores de EC, sendo 7,4 e 9,8 MJ ha ${ }^{-1}$, respectivamente. A média total anual de EC foi de 5,5 $\mathrm{MJ}$ ha $^{-1}$.

As maiores intensidades médias mensais foram observadas em fevereiro para as chuvas de padrão avançado $\left(28,6 \mathrm{~mm} \mathrm{~h}^{-1}\right)$ e em janeiro, para as do intermediário e do atrasado, sendo 21,2 e 20,6, respectivamente. Os meses de janeiro e fevereiro apresentaram média igual para o $\mathrm{I}_{30}$ de $24,4 \mathrm{~mm} \mathrm{~h}^{-1}$. A média total de intensidade média para as chuvas erosivas foi de $17,4 \mathrm{~mm} \mathrm{~h}^{-1}$. A média anual foi de 20,$3 ; 14,4$; e $13,7 \mathrm{~mm} \mathrm{~h}^{-1}$, respectivamente para os padrões avançado, intermediário e atrasado. Resultados semelhantes foram obtidos por Eltz et al. (2011), que constataram distribuição mais desigual do potencial erosivo em relação aos padrões de chuva em Encruzilhadinha do Sul, RS, ocorrendo com 55, 27 e $18 \%$ para os padrões avançado, intermediário e atrasado, respectivamente.

Quadro 2. Duração média e energia cinética média das chuvas erosivas registradas em Urussanga, SC, no período de outubro de1980 a março de 2012

\begin{tabular}{|c|c|c|c|c|c|c|c|c|}
\hline \multirow{3}{*}{ Mês } & \multicolumn{8}{|c|}{ Padrão de chuva erosiva } \\
\hline & Avançado & Intermediário & Atrasado & Total & Avançado & Intermediário & Atrasado & Total \\
\hline & \multicolumn{4}{|c|}{ Duração média } & \multicolumn{4}{|c|}{ Energia cinética média } \\
\hline & & $\mathrm{h}-$ & 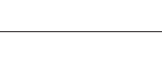 & - & 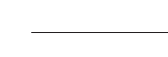 & MJ ha & & \\
\hline Jan. & 11,2 & 12,7 & 10,8 & 11,7 & 6,6 & 5,7 & 5,2 & 6,1 \\
\hline Fev. & 9,8 & 13,3 & 12,7 & 11,2 & 6,6 & 6,2 & 4,1 & 6,1 \\
\hline Mar. & 11,6 & 12,9 & 13,0 & 12,1 & 6,4 & 4,8 & 3,7 & 5,7 \\
\hline Abr. & 10,0 & 15,3 & 14,5 & 12,6 & 5,8 & 5,0 & 4,6 & 5,3 \\
\hline Mai. & 19,7 & 21,0 & 21,7 & 20,4 & 5,9 & 7,4 & 9,8 & 6,9 \\
\hline Jun. & 14,3 & 18,3 & 13,5 & 15,6 & 4,2 & 5,8 & 2,3 & 4,5 \\
\hline Jul. & 13,2 & 20,9 & 17,3 & 17,9 & 4,2 & 5,3 & 2,7 & 4,7 \\
\hline Ago. & 16,7 & 19,3 & 17,9 & 17,8 & 5,0 & 5,9 & 4,4 & 5,2 \\
\hline Set. & 19,5 & 16,6 & 23,2 & 19,0 & 5,7 & 3,8 & 5,6 & 4,9 \\
\hline Out. & 12,7 & 16,5 & 16,2 & 14,3 & 5,0 & 5,4 & 3,7 & 5,0 \\
\hline Nov. & 13,2 & 15,0 & 15,6 & 14,0 & 5,1 & 4,0 & 4,4 & 4,7 \\
\hline Dez. & 11,8 & 15,9 & 11,2 & 13,1 & 5,8 & 6,9 & 4,3 & 6,0 \\
\hline Ano & 13,0 & 16,3 & 15,2 & 14,4 & 5,7 & 5,5 & 4,5 & 5,5 \\
\hline
\end{tabular}


Quadro 3. Intensidade máxima em $30 \mathrm{~min}\left(\mathrm{I}_{30}\right)$ média e erosividade das chuvas $\left(\mathrm{EI}_{30}\right)$ média da chuva erosiva registradas em Urussanga, SC, no período de outubro de1980 a março de 2012

\begin{tabular}{|c|c|c|c|c|c|c|c|c|}
\hline \multirow{3}{*}{ Mês } & \multicolumn{8}{|c|}{ Padrão de chuva erosiva } \\
\hline & Avançado & Intermediário & Atrasado & Total & Avançado & Intermediário & Atrasado & Total \\
\hline & \multicolumn{4}{|c|}{$\mathbf{I}_{30}$} & \multicolumn{4}{|c|}{$\mathbf{E I}_{30}$} \\
\hline & \multicolumn{4}{|c|}{$-\mathrm{mm} \mathrm{h}^{-1}$} & \multicolumn{4}{|c|}{$-\mathrm{MJ} m \mathrm{ha}^{-1} \mathrm{~h}^{-1}$} \\
\hline Jan. & 26,9 & 21,2 & 20,6 & 24,4 & 224,2 & 175,0 & 167,8 & 202,3 \\
\hline Fev. & 28,6 & 19,8 & 17,4 & 24,4 & 254,4 & 181,9 & 94,5 & 211,0 \\
\hline Mar. & 26,3 & 17,4 & 13,9 & 22,7 & 205,7 & 102,8 & 58,9 & 163,0 \\
\hline Abr. & 23,0 & 18,1 & 16,6 & 20,3 & 197,4 & 113,7 & 99,2 & 152,4 \\
\hline Mai. & 10,2 & 12,5 & 15,3 & 11,6 & 82,2 & 128,5 & 217,4 & 112,5 \\
\hline Jun. & 10,8 & 11,0 & 7,6 & 10,4 & 51,8 & 75,9 & 19,1 & 55,3 \\
\hline Jul. & 9,6 & 10,0 & 7,9 & 9,7 & 46,4 & 63,4 & 22,8 & 54,1 \\
\hline Ago. & 12,1 & 10,2 & 11,0 & 11,2 & 70,1 & 92,9 & 72,1 & 78,9 \\
\hline Set. & 10,8 & 8,9 & 10,6 & 10,1 & 85,0 & 37,3 & 76,5 & 65,3 \\
\hline Out. & 14,9 & 13,0 & 7,7 & 13,6 & 92,8 & 88,0 & 35,2 & 85,3 \\
\hline Nov. & 19,7 & 11,2 & 12,1 & 16,4 & 126,3 & 58,0 & 86,6 & 102,3 \\
\hline Dez. & 25,1 & 16,3 & 15,7 & 20,9 & 228,9 & 139,6 & 72,9 & 179,1 \\
\hline Ano & 20,3 & 14,4 & 13,7 & 17,4 & 159,1 & 107,3 & 85,8 & 132,2 \\
\hline
\end{tabular}

Os resultados de erosividade média por padrão para as chuvas erosivas apresentam-se no quadro 3. No mês de fevereiro foi registrada a maior média mensal de erosividade para as chuvas dos padrões avançado e intermediário, respectivamente 254,4 e $181,9 \mathrm{MJ} \mathrm{mm} \mathrm{ha}^{-1} \mathrm{~h}^{-1}$.

No padrão atrasado, o mês com maior média de erosividade foi maio $\left(217,4 \mathrm{MJ} \mathrm{mm} \mathrm{ha}^{-1} \mathrm{~h}^{-1}\right)$. Analisando as médias totais, o mês de fevereiro também se destacou com média total de erosividade de $211 \mathrm{MJ} \mathrm{mm} \mathrm{ha}{ }^{-1} \mathrm{~h}^{-1}$. A maior média anual foi obtida para as chuvas de padrão avançado (159,1 MJ mm ha-1 $\left.\mathrm{h}^{-1}\right)$, seguida pelo intermediário (107,3 $\mathrm{MJ} \mathrm{mm} \mathrm{ha}^{-1} \mathrm{~h}^{-1}$ ) e atrasado $\left(85,8 \mathrm{MJ} \mathrm{mm} \mathrm{ha}^{-1} \mathrm{~h}^{-1}\right)$.

Na figura 1,são representadas as frequências de ocorrências das intensidades máximas em 30 min das chuvas erosivas, segundo o padrão de distribuição. As chuvas do padrão avançado apresentaram maior frequência que as do padrão intermediário e do atrasado. Dessa forma, observa-se que $20 \%$ das chuvas do padrão avançado apresentam intensidade máxima de $30 \mathrm{~min}$ acima de $30 \mathrm{~mm} \mathrm{~h}^{-1}$; para os padrões intermediárioe atrasados, a intensidade superada por $20 \%$ dos eventos é de $20 \mathrm{~mm} \mathrm{~h}^{-1}$.

Os resultados da frequência de chuvas erosivas conforme a duração e o padrão são evidenciados no quadro 4. Do total de 1.221 chuvas erosivas, $41(3,4 \%)$ tiveram duração inferior a $2 \mathrm{~h}$. Dessas, 38 (92,7 \%) foram do padrão avançado, três do intermediário e zero do atrasado. A maior concentração de chuvas $(32,9 \%)$ foi observada no intervalo de duração de 6 a 12 h. Pode-se observar que para duração inferior a $18 \mathrm{~h}$ ocorre maior frequência de chuvas do padrão avançado; para durações acima de $18 \mathrm{~h}$, as

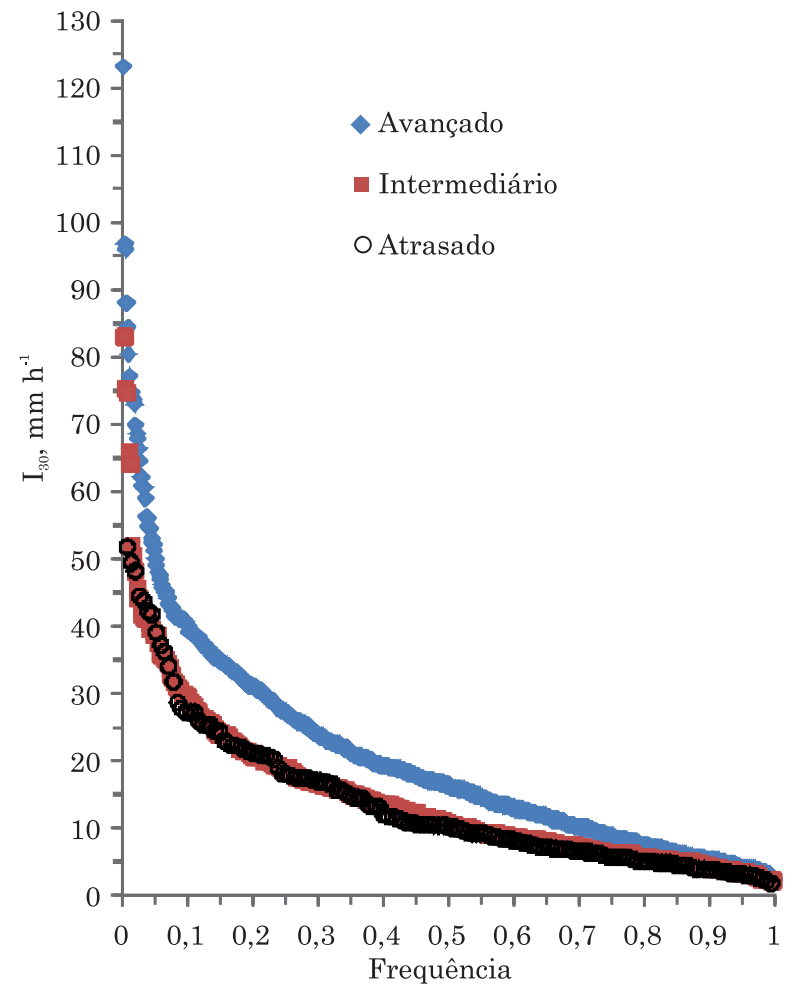

Figura 1. Frequência das intensidades máximas em $30 \min \left(\mathrm{I}_{30}\right)$ das chuvas erosivas de Urussanga, SC, segundo padrão de distribuição temporal.

frequências de chuvas do padrão avançado e do intermediário são semelhantes. Em todas as durações, as chuvas do padrão atrasado foram as menos frequentes. 
Quadro 4. Frequência e erosividade média de chuvas erosivas, de acordo com a duração e o padrão de chuvas

\begin{tabular}{|c|c|c|c|c|c|c|c|c|}
\hline \multirow{3}{*}{ Duração } & \multicolumn{8}{|c|}{ Padrão de chuva erosiva } \\
\hline & Avançado & Intermediário & Atrasado & Total & Avançado & Intermediário & Atrasado & Total \\
\hline & \multicolumn{4}{|c|}{ Frequência } & \multicolumn{4}{|c|}{ Erosividade média } \\
\hline $\mathrm{h}$ & $\longrightarrow$ & $\%-$ & 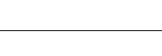 & 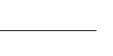 & $\longrightarrow$ & $\mathrm{MJ} \mathrm{mm}$ ha & $h^{-1}$ & \\
\hline$<2$ & 38 & 3 & 0 & 41 & 177,3 & 504,8 & 0,0 & 682,0 \\
\hline 2 a 6 & 120 & 52 & 22 & 194 & 181,1 & 125,1 & 125,6 & 431,8 \\
\hline 6 a 12 & 221 & 129 & 52 & 402 & 155,6 & 67,2 & 60,8 & 283,7 \\
\hline 12 a 18 & 132 & 94 & 37 & 263 & 109,9 & 80,6 & 54,1 & 244,6 \\
\hline 18 a 24 & 64 & 68 & 19 & 151 & 104,1 & 82,0 & 78,4 & 264,4 \\
\hline 24 a 48 & 66 & 57 & 23 & 146 & 235,5 & 171,2 & 154,3 & 561,0 \\
\hline$>48$ & 10 & 13 & 1 & 24 & 400,4 & 388,8 & 253,5 & 1042,7 \\
\hline
\end{tabular}

A erosividade média de chuvas erosivas, conforme duração e padrão, encontram-se no quadro 4. Para chuvas com duração menor do que $2 \mathrm{~h}$, a maior média de erosividade foi obtida no padrão intermediário; no entanto, como foram somente três eventos do padrão intermediário e 38 do avançado, não se pode comparar as médias. Para as demais durações, a erosividade média é maior nas chuvas de padrão avançado, em razão da maior intensidade dessas chuvas.

\section{CONCLUSÕES}

1. As chuvas erosivas, durante o período de estudo, ocorreram 1.221, das quais 651 foram de acordo com o perfil avançado; 416, intermediário; e 154, atrasado.

2. A duração média das chuvas erosivas foi de 14,4 $\mathrm{h}$, sendo a média de $13,0 \mathrm{~h}$ para as de padrão atrasado; $16,3 \mathrm{~h}$, para as de padrão intermediário; e 15,2 h, para as de padrão atrasado.

3. A média total de intensidade média para as chuvas erosivas foi de $17,4 \mathrm{~mm} \mathrm{~h}^{-1}$. A média anual foi de 20,$3 ; 14,4$; e $13,7 \mathrm{~mm} \mathrm{~h}^{-1}$, respectivamente para os padrões avançado, intermediário e atrasado.

4. A maior concentração de chuvas (32,9\%) foi observada no intervalo de duração de 6 a 12 h. Do total de 1.221 chuvas erosivas, 41 (3,4 \%) tem duração inferior a $2 \mathrm{~h}$.

5. As chuvas do padrão avançado ocorrem com maior periodicidade, numa duração inferior a $18 \mathrm{~h}$. Para acima de $18 \mathrm{~h}$, as frequências das dos padrões avançado e intermediário são semelhantes. Em todas as durações, as chuvas do padrão atrasado são as menos frequentes.

6. As chuvas erosivas se concentraram nos meses da estação de verão, com menor duração e maior intensidade em relação às que ocorreram na estação de inverno.

\section{LITERATURA CITADA}

ARAÚJO, G.H.S.; ALMEIDA, J.R. \& GUERRA, A.J.T. Gestão ambiental de áreas degradadas. Rio de Janeiro, Bertrand Brasil, 2005. 320p.

ARROIO JR, P.P.; RODRIGUES, T.; KUWAJIMA, J.I. \& MAUAD, F.F. Avaliação espaço-temporal da perda de solo por erosão laminar na bacia hidrográfica do reservatório do Broa, municípios de Itirapina e Brotas - SP. In: ENCONTRO NACIONAL DE ENGENHARIA DE SEDIMENTOS, 10., 2012. Anais... Foz do Iguaçu, ABRH, 2012. CD ROM

BACK, Á.J. Time distribution of heavy rainfall events in Urussanga, Santa Catarina State, Brazil. Sci. Agron., 33:583-588, 2011.

BEMFICA, D.C.; GOLDENFUM, J.A. \& SILVEIRA, A.L.L. Análise da aplicabilidade de padrões de chuva de projeto a Porto Alegre. R. Bras. Rec. Hídr.,5:5-16, 2000.

CABEDA, M.S.V. Computation of storm EI values. West Lafayette, Purdue University, 1976. 6p.

CARVALHO, D.F.; MONTEBELLER, C.A.; FRANCO, E.M.; VALCARCEL, R. \& BERTOL, I. Padrões de precipitação e índices de erosividade para as chuvas de Seropédica e Nova Friburgo, RJ. R. Bras. Eng. Agric. Amb., 9:7-14, 2005.

CARVALHO, N.O. Hidrossedimentologia prática. 2.ed. Rio de Janeiro, Interciência, 2008. 599p.

CASSOL, E.A.; ELTZ, F.L.F.; MARTINS, D.; LEMOS, A.M.; LIMA, V.D. \& BUENO, A.C. Erosividade, padrões hidrológicos, período de retorno e probabilidade de ocorrência das chuvas em São Borja, RS. R. Bras. Ci. Solo, 32:1239-1251, 2008.

DUFLOTH, J.H.; CORTINA, N.; VEIGA; M. \& MIOR, L.C. Estudos básicos regionais de Santa Catarina. Florianópolis, EPAGRI, 2005. CD-ROM

EMPRESA BRASILEIRA DE PESQUISA AGROPECUÁRIA . EMBRAPA. Centro Nacional de Pesquisa de Solos. Sistema brasileiro de classificação de solos. Brasília, Sistema de Produção e Informação, 1999. 212p 
ELTZ, F.L.F.; CASSOL, E.A. \& PASCOTINI, P.B. Potencial erosivo e características das chuvas de Encruzilhadinha do Sul, RS. R. Bras. Eng. Agric. Amb., 15:331-337, 2011.

ELTZ, F.L.F.; MEHL, H. U. \& REICHERT, J.M. Perdas de solo e água em entressulcos em um Argissolo VermelhoAmarelo submetido a quatro padrões de chuvas. R. Bras. Ci. Solo, 25:485-493, 2001.

EVANGELISTA, A.W.P.; CARVALHO, L.G. \& BERNARDINO, D.T. Caracterização do padrão das chuvas ocorrentes em Lavras, MG. Irriga, 10:306-317, 2005.

HORNER, W.W. \& JENS, S.W. Surface runoff determination from rainfall without using coefficients. Trans. ASAE, 107:1039-1117, 1942 .

HUFF, F.A. Time distribution of rainfall in heavy storms. Water Resour. Res., 3:1007-1019, 1967.

LIMA, E.R.V. Erosão do solo: Fatores condicionantes e modelagem matemática. Disponível em: <http:// www.geociencias.ufpb.br/logepa/revistas/pesquisa/ ano1_n1/ano1_n1_artigo1.htm>. Acesso em: 12 maio 2011.

MAGALHÃES FILHO, F.J.C.; MAACHAR, A.F.; AYRES, F.M. \& A SOBRINHO, T. Integrando SIG e USLE para mapeamento da perda de solo em área de proteção ambiental. In: ENCONTRO NACIONAL DE ENGENHARIA DE SEDIMENTOS, 10., Foz do Iguaçu, 2012. Anais... Foz do Iguaçu, ABRH, 2012. CD-ROM
MARTINS, D.; CASSOL, E.A.; ELTZ, F.L.F. \& BUENO, A.C. Erosividade e padrões hidrológicos das chuvas de Hulha Negra, Rio Grande do Sul, Brasil, com base no período de 1956 a 1984. Pesq. Agropec. Gaúcha, 15:29-38, 2009.

MEHL, H.U.; REICHERT, J.M. \& DIDONÉ, I.A. Caracterização de padrões de chuvas ocorrentes em Santa Maria (RS). R. Bras. Ci. Solo, 25:475-483, 2001.

MENDES, C.A.R. Erosão superficial em encosta íngreme sob cultivo perene e com pousio no município de Bom Jardim - RJ. Rio de Janeiro, Universidade Federal do Rio de Janeiro, 2006. 236p. (Tese de Doutorado)

PEDROLLO, O.C. GEDAC:Gerenciamento de dados contínuos. Manual do usuário. Porto Alegre, IPH, 1997. 60 p.

PRUSKI, F.F. Conservação do solo e água: práticas mecânicas para o controle da erosão hídrica. 2.ed. Viçosa, MG, Universidade Federal de Viçosa, 2009. 279p.

SALOMÃO, F.X.T. Controle e Prevenção dos processos erosivos. In: GUERRA, A.J.T.; SILVA, A.S. \& BOTELHO, R.G.M., orgs. Erosão e conservação dos solos: Conceitos, temas e aplicações. Rio de Janeiro, Bertrand Brasil, 1999. p.230-267.

WISCHMEIER, W.H. \&SMITH, D.D. Predicting rainfall erosion losses: A guide to conservation planning. Washington, USDA, 1978. 58p. (Agriculture Handbook, 5) 